\title{
Research Article \\ Selecting e-Purse Smart Card Technology via Fuzzy AHP and ANP
}

\author{
Nurgül Demirtaş, Şenim Özgürler, Mesut Özgürler, and Ali Fuat Güneri
}

Department of Industrial Engineering, Yildiz Technical University, 34349 Istanbul, Turkey

Correspondence should be addressed to Şenim Özgürler; senimozgurler@hotmail.com

Received 19 November 2013; Accepted 9 March 2014; Published 1 June 2014

Academic Editor: Huijun Gao

Copyright (C) 2014 Nurgül Demirtaş et al. This is an open access article distributed under the Creative Commons Attribution License, which permits unrestricted use, distribution, and reproduction in any medium, provided the original work is properly cited.

\begin{abstract}
Developments in the information technologies provide important advantages to consumers and companies. Nowadays, smart card technology starts to use e-purse applications. The aim of this paper is to identify the most important decision criteria to select the best card technology. In this study, at first smart card and multiple selection techniques were explained. Then the best card technology was selected for an e-purse application. The three types of card technologies were examined and the most important criteria were taken into account by the software developer while they develop card software. Fuzzy analytic hierarchy process (FAHP) and analytical network process (ANP) techniques were used to compare smart card technologies.
\end{abstract}

\section{Introduction}

Analysis with single parameter or criterion is not enough to resolve the complex structured problem parallel to the development of science and technology. The most significant inference of the single-criteria analysis is to accept the other dimensions of the event as static and to examine only one factor for each time. However, the events and the objects occur under the influences of a huge amount of internal and external factors instead of a solitary factor and demonstrate complex formation. Because of this reason, events and objects must be defined according to the amount of agents and their collective efficiency rather than a single agent [1]. Due to these factors, multiple parameter judgment methods are applied in almost every field. And one of these fields is smart card technology.

Usage and effectiveness of internet is increasing day by day. One of the important results of this frequency is that the commerce is moving to the electronic environment. Transferring the development of the information technologies to trade is effectively beneficial for both consumers and companies. Smart card technology has been built up because of the necessities plus these benefits. Development of the smart card technologies has been increasing since it started to be used in 2002 in the world and Turkey.
Smart card is being used in lots of fields including health, security, retail, telecom, banking, government, and automotive field. Beside this functional usage, innovative approaches have been explored while traditional boundaries were passed over in retail segment. While exploring these approaches, technological improvement and especially development in the information technologies are used as exploitable.

Developing smart card application including card payment system and card personalization should demonstrate multicriteria structure. Multiple parameter judgment methods are appropriate for smart card technology and by using these methods choice of smart card technologies should present more sensible decisions and suggestions.

The rest of the paper is arranged as follows. The smart card technology which is appropriate for developing e-purse application is presented in Section 2. In Sections 3 and 4, FAHP and ANP methods are explained, respectively. In Section 5, these methods are applied in order to select e-purse smart card technology. Finally, the results of the paper and future study suggestions are considered in the last section.

\section{Smart Card Concept and Properties}

2.1. Smart Card Concept. Technological development is kind of "minimizing automation system" process. Communication 


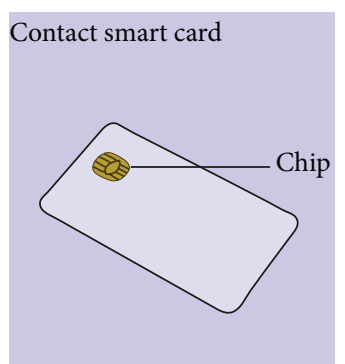

(a)

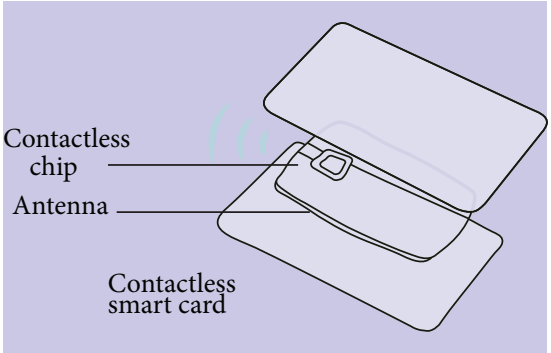

(b)

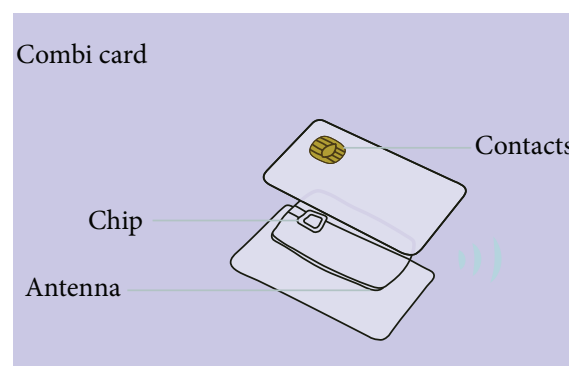

(c)

Figure 1: (a) Contact smart card, (b) contactless smart card, and (c) combi card.

technologies like cell phones, small but functional computer systems, microchips managing and controlling huge mechanisms, and database units are the examples of this minimizing automation. Smart card would be included in this minimizing automation process.

Smart card technology has evolved a long way since the idea of using plastic cards to carry microelectronic chips was patented back in 1968 by Dethloff and Grötrupp [2]. A smart card is a credit-card sized plastic card with an embedded computer chip that can be memory or also include a microprocessor [3-5]. A microprocessor chip can add, delete, and otherwise manipulate information in its memory and hence offer complex data security schemes [4]. Smart card technology can enable an organization to become more secure, efficient, and interoperable while delivering strong authentication and security, identity management, data management, customer support, and communications [6]. The card body is usually more than just a carrier for the chip module. It also includes information for the user and card accepters and of course security elements for protection against forgery. The card elements are printing and labeling, embossing, hologram, signature panel, tactile elements, magnetic stripe, chip module, and antenna [7]. Smart cards, the result of evolution of magnetic card in use of daily life, have superior memory than magnetic cards. This vast memory provides ability to execute lots of functions and present complex result. As a result of this condition, a database for customer relationship management (CRM) and statistical data network can be provided by installing all of the information of any customer. Also it becomes easy to reach customer almost in every branch of business like health, automotive, and retail sector.

2.2. Smart Card Types. A smart-card chip communicates with a reader by direct physical contact or by a radio frequency (RF) signal, depending on the system design [8]. Smart cards are grouped into three classes for chip-toreader communications which are (1) contact smart cards, (2) contactless smart cards, and (3) combi cards.

2.2.1. Contact Smart Cards. Contact smart cards are the most popular card-connection design and are used for both card sizes and chip types. Figure 1(a) [9] depicts the contact-type card [8]. Contact cards use an eight-pin contact micromodule to physically connect to the card reader [8].

2.2.2. Contactless Smart Cards. Contactless smart cards as shown in Figure 1(b) [9] use an antenna with approximately a 10 -centimeter $(\mathrm{cm})$ range to communicate with the reader. These credit-card sized memory-chip devices derive their power from an RF field generated by the card reader. The RF field also transfers information to and from the card and card reader [8]. Contactless cards are better suited for environments where quick interaction between the card and reader is required, such as high-volume physical access [10]. Employee identification badges issued by large companies for building access are typically contactless smart cards [8].

2.2.3. Combination Smart Cards. Multipurpose combination smart cards are a hybrid mix of the contact and contactless designs [8]. These cards obtain the two systems described above. These cards contain all the properties of the other two types. Figure 1(c) shows the combination smart card [9]. They include the eight-pin contact for communication with a contact-type reader and also include an antenna for communication with an RF-type reader [8]. With such a card, it becomes possible to access the same chip via a contact and contactless interface, with a very high level of security. It may incorporate two noncommunicating chips-one for each interface-but preferably has a single, dual interface chip providing the many advantages of a single e-purse, single operating architecture, and so forth. The mass transportation and banking industries are expected to be the first to take advantage of this technology [9].

\subsection{Advantages and Usage Areas of Smart Card Technologies.} Smart card automation process has lots of function such as; to prevent time lost, to reach customer, to control efficiency. Working level becomes mobilized with smart cards. This means workplace is not bounded to an only place and customers are reached every time. Briefly, customer relationship management becomes the focus of business and production process and its effectiveness increases. Smart card usage provides trust and prestige to company or company's institutional identity. Smart cards are more secure than magnetic cards. The highly developed software of smart cards 
raises security level. In case smart cards are obtained by third person, risk of data theft is decreased by the software that prevents copying data and protects the cryptology algorithm. Information stored in smart cards is protected by complex security mechanism. Because of this reason it is hard and expensive to copy or change data. Progression to smart card from magnetic cards decreases the card forgery caused by both fake cards and offline card process. During the mobilized usage, the most important necessities are data security and accuracy. Disability to copy and change data in the card and to reach data during service is the most significant property. It is vital to protect both card owner and service provider. Smart cards can protect data by the help of private hardware and software and can apply well developed cryptology methods.

Clearly there are beneficial outcomes from the application of smart cards. Realizing these benefits both for individuals and organizations may well profoundly change the relationship between clients or consumers and suppliers or government bodies. A smart card that is your passport, driving license, credit and debit card, and access to your place of work and your car ignition key will undoubtedly alter relationships due to potential uneasiness about what data is held, accessed, and modified [11]. Some of the potential benefits of smart cards are as follows. Using smart cards is safer than carrying cash for an individual, smart cards can improve access to services for the disabled and elderly, it is a secure means of authenticating the identity of reader device, it is a portable and secure store of information available to all, access can be made available in geographical locations where online communication is not possible, the opportunity of fraud is reduced using smart cards, social disadvantaged groups can gain access to facilities and resources without feeling stigmatized, and objective selection criteria can be upheld and the risk of bias or favouritism reduced [11].

Smart cards have a wide range of potential applications and can be utilized for many different purposes. However, there are unquestionably areas that are especially suitable for smart cards. The principal characteristics of smart cards are that they can securely store relatively small amounts of data and provide an environment for the secure execution of programs. This makes them excellent candidates for use in the entire security sector. Another important characteristic is that they have a well-established format that is convenient for manual use and handling. Although the smart card interface does not correspond to the current PC and Internet standards, it is still easy to use, which also encourages the use of smart cards. The best possible uses for smart cards are applications that need a large number of inexpensive data storage devices that can securely store individual or personal data and that must perform security-related activities such as authentication, encryption, and/or signing [7].

In summary, the range of smart card applications is growing for many reasons such as security, multiple application, and portability. Smart cards are used in many different applications around the world, particularly for electronic payment, security and authentication, transportation, telecommunications, health care, loyalty programs, and education. These are some of the more popular application areas [12]. It is

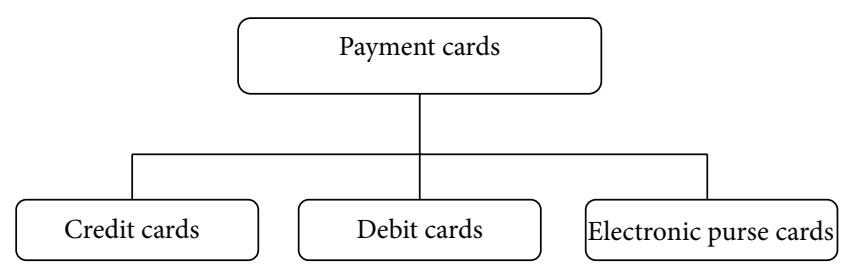

FIGURE 2: Classification of payment cards.

important to note that consumer acceptance and confidence are crucial for the further development of smart card technology as the underlying issues which demand more control, security, privacy, flexibility, and ease of use [12].

2.4. Smart Card as Electronic Purse. The original primary application of smart cards with microcontrollers was user identification in the telecommunications sector. In recent years, however, smart cards have established themselves in another market sector, namely, electronic payment systems. Due to the large number of cards in use, the market potential of this sector is enormous. Smart cards are by nature particularly suitable for payment system applications. They can easily and securely store data, and their convenient size and robustness make them easy for everyone to use. Since smart cards can also actively perform complicated computations without being influenced by external factors, it is possible to develop totally new approaches to performing payment transactions [3].

The idea of implementing an electronic purse in a smart card goes back to the early days of smart card technology. However, only since the mid-1990s has this concept been realized, since that was when the development of large systems first began. Electronic payment systems and electronic purses offer significant benefits to everyone involved. For banks and merchants, they reduce the costs associated with handling cash. Offline electronic purses largely eliminate the costs of data telecommunications for payment transactions. The risk of robbery and vandalism is reduced, since electronic systems contain no cash to be stolen. For merchants, the fact that transactions are processed more quickly is also a persuasive argument, since it means that cash management can be optimized. Classification of payment cards and e-purse systems based on smart cards is shown in Figures 2 and 3, respectively [3].

\section{Fuzzy AHP Methodology}

There has been growth in the number of multiple criteria decision-making methods for assisting decision making during the past two decades. These allow decision makers to evaluate various alternatives for achieving their goal [13].

Analytic hierarchy process (AHP) is a simple decisionmaking tool to deal with complex, unstructured, and multiattribute problems [14] or a weight estimation technique in many areas such as selection, evaluation, planning and development, decision making, and forecasting. The traditional AHP requires crisp judgments. However, due to 


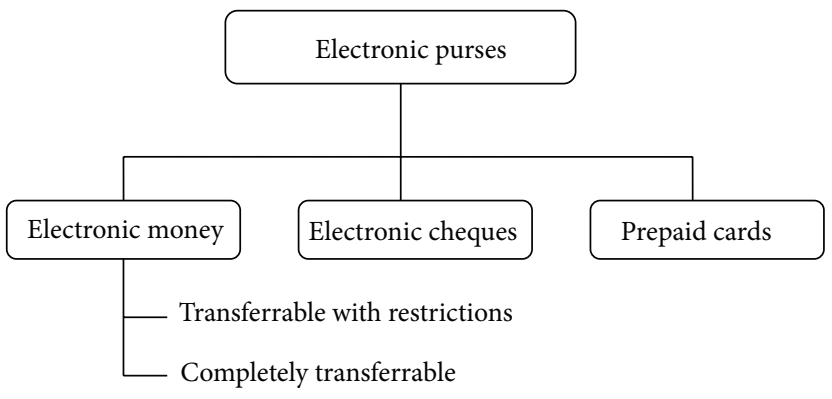

Figure 3: Classification of electronic purse systems based on smart cards.

the complexity and uncertainty involved in real world decision problems, a decision maker (DM) may sometimes feel more confident to provide fuzzy judgments than crisp comparisons [15].

The fuzzy analytic hierarchy process (FAHP) is one of the most popular [13] of methods that have been developed to handle fuzzy comparison matrices $[15,16]$. The FAHP methodology extends Saaty's AHP by combining it with the fuzzy set theory. In the FAHP, fuzzy ratio scales are used to indicate the relative strength of the factors in the corresponding criteria. Therefore, a fuzzy judgment matrix can be constructed. The final scores of alternatives are also represented by fuzzy numbers. The optimum alternative is obtained by ranking the fuzzy numbers using special algebra operators [17]. There are many FAHP methods proposed by various authors. These methods are systematic approaches to the alternative selection and justification problem by using the concepts of fuzzy set theory and hierarchical structure analysis [18, 19]. Decision makers usually find that it is more confident to give interval judgments than fixed value judgments. This is because usually he/she is unable to be explicit about his/her preferences due to the fuzzy nature of the comparison process $[16,18,19]$. The earliest work in FAHP appeared in van Laarhoven and Pedrycz [20], which compared fuzzy ratios described by triangular membership functions $[18,19,21]$. Buckley [22] determines fuzzy priorities of comparison ratios whose membership functions are trapezoidal $[18,19,21]$. Chang (1996) introduces a new approach for handling fuzzy AHP, with the use of triangular fuzzy numbers for pairwise comparison scale of fuzzy AHP and the use of the extent analysis method for the synthetic extent values of the pair-wise comparisons [18, 19]. Zhang et al. (2013) proposed a multiple attribute decision making model to seek the node importance of complex networks in product research and development team [23]. W. Zhang and Q. Zhang (2013) constructed a multistage evaluation criteria system from the three dimensions of novelty, value, and practicality, each of which is composed of three separate evaluation criteria system, and the fuzzy AHP method is applied to obtain the weights of each dimension and subdimension [24].

In this study, Chang's extent analysis [25] is used. In the following, the steps of the extent analysis method on FAHP are given.
Let $X=\left\{x_{1}, x_{2}, \ldots, x_{n}\right\}$ be an object set, and let $U=$ $\left\{u_{1}, u_{2}, \ldots, u_{m}\right\}$ be a goal set. According to the method of Chang's extent analysis, each object is taken and extent analysis for each goal, $g_{i}$, is performed, respectively. Therefore, $m$ extent analysis values for each object can be obtained, with the following signs:

$$
M_{g_{i}}^{1}, M_{g_{i}}^{2}, \ldots, M_{g_{i}}^{m}, \quad i=1,2, \ldots, n,
$$

where all the $M_{g_{i}}^{j}(j=1,2, \ldots, m)$ are triangular fuzzy numbers.

The steps of Chang's extent analysis can be detailed as follows [16, 18, 19, 21, 25-28].

Step 1. The value of fuzzy synthetic extent with respect to the $i$ th object is defined as

$$
S_{i}=\sum_{j=1}^{m} M_{g_{i}}^{j} \otimes\left[\sum_{i=1}^{n} \sum_{j=1}^{m} M_{g_{i}}^{j}\right]^{-1} .
$$

To obtain $\sum_{j=1}^{m} M_{g_{i}}^{j}$, perform the fuzzy addition operation of $m$ extent analysis values for a particular matrix such that

$$
\sum_{j=1}^{m} M_{g_{i}}^{j}=\left(\sum_{j=1}^{m} l_{j}, \sum_{j=1}^{m} m_{j}, \sum_{j=1}^{m} u_{j}\right),
$$

and to obtain $\left[\sum_{i=1}^{n} \sum_{j=1}^{m} M_{g_{i}}^{j}\right]^{-1}$, perform the fuzzy addition operation of $M_{g_{i}}^{j}(j=1,2, \ldots, m)$ values such that

$$
\sum_{i=1}^{n} \sum_{j=1}^{m} M_{g_{i}}^{j}=\left(\sum_{i=1}^{n} l_{i}, \sum_{i=1}^{n} m_{i}, \sum_{i=1}^{n} u_{i}\right)
$$

and then compute the inverse of the vector in (4) such that

$$
\left[\sum_{i=1}^{n} \sum_{j=1}^{m} M_{g_{i}}^{j}\right]^{-1}=\left(\frac{1}{\sum_{i=1}^{n} u_{i}}, \frac{1}{\sum_{i=1}^{n} m_{i}}, \frac{1}{\sum_{i=1}^{n} l_{i}}\right) .
$$

Step 2. The degree of possibility of $M_{2}=\left(l_{2}, m_{2}, u_{2}\right) \geq M_{1}=$ $\left(l_{1}, m_{1}, u_{1}\right)$ is defined as

$$
V\left(M_{2} \geq M_{1}\right)=\sup _{y \geq x}\left[\min \left(\mu_{M_{1}}(x), \mu_{M_{2}}(y)\right)\right]
$$

and can be equivalently expressed as follows:

$$
\begin{aligned}
& V\left(M_{2} \geq M_{1}\right)=\operatorname{hgt}\left(M_{1} \cap M_{2}\right)=\mu_{M_{2}}(d) \\
& V\left(M_{2} \geq M_{1}\right)= \begin{cases}1 ; & \text { if } m_{2} \geq m_{1}, \\
0 ; & \text { if } l_{1} \geq u_{2}, \\
\frac{l_{1}-u_{2}}{\left(m_{2}-u_{2}\right)-\left(m_{1}-l_{1}\right)} ; & \text { otherwise, }\end{cases}
\end{aligned}
$$

where $d$ is the ordinate of the highest intersection point $D$ between $\mu_{M_{1}}$ and $\mu_{M_{2}}$ (see Figure 4 ). 


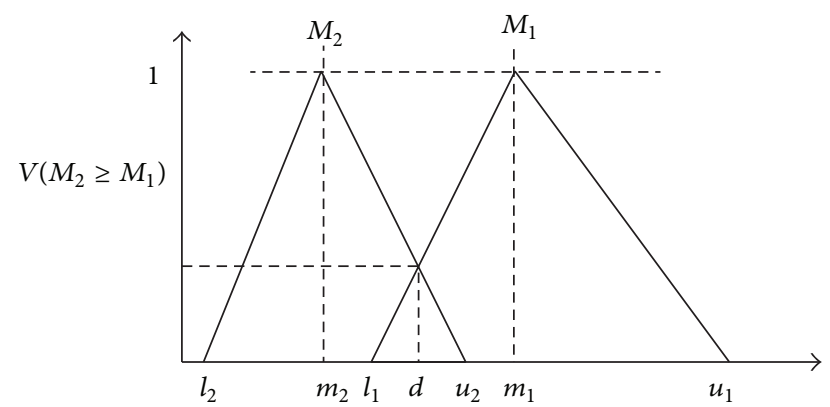

Figure 4: The intersection between $M_{1}$ and $M_{2}$.

To compare $M_{1}$ and $M_{2}$, both the values of $V\left(M_{1} \geq M_{2}\right)$ and $V\left(M_{2} \geq M_{1}\right)$ are required. The intersection between $M_{1}$ and $M_{2}$ is shown in Figure 4 [18].

Step 3. The degree possibility for a convex fuzzy numberto be greater than $k$ convex fuzzy numbers $M_{i}(i=1,2, \ldots, k)$ can be defined by

$$
\begin{aligned}
V & \left(M \geq M_{1}, M_{2}, \ldots, M_{k}\right) \\
& =V\left[\left(M \geq M_{1}\right) \text { and }\left(M \geq M_{2}\right) \text { and, } \ldots, \text { and }\left(M \geq M_{k}\right)\right] \\
& =\min V\left(M \geq M_{i}\right), \quad i=1,2,3, \ldots, k .
\end{aligned}
$$

Assume that

$$
d^{\prime}\left(A_{i}\right)=\min V\left(S_{i} \geq S_{k}\right) .
$$

For $k=1,2, \ldots, n ; k \neq i$. Then, the weight vector is given by

$$
W^{\prime}=\left(d^{\prime}\left(A_{1}\right), d^{\prime}\left(A_{2}^{\prime}\right), \ldots, d^{\prime}\left(A_{n}\right)\right)^{T},
$$

where $A_{i}(i=1,2, \ldots, n)$ are $n$ elements.

Step 4. Via normalization, the normalized weight vectors are

$$
W=\left(d\left(A_{1}\right), d\left(A_{2}\right), \ldots, d\left(A_{n}\right)\right)^{T},
$$

where $W$ is a nonfuzzy number.

\section{Analytic Network Process (ANP)}

The ANP is the most comprehensive framework for analysis of public, governmental, and corporate decisions. It allows decision makers to include all the factors and tangible or intangible criteria that have a bearing on making the best decision [29].

Many decision problems cannot be structured hierarchically because they involve the interaction and dependence of higher-level elements on lower-level elements [30,31]. Not only does the importance of the criteria determine the importance of the alternatives as in a hierarchy, but also the importance of the alternatives themselves determines the importance of the criteria [30].
The ANP generalizes a widely used multicriteria decision making tool, the AHP, by replacing hierarchies with networks. The AHP is a well-known technique that decomposes a problem into several levels in such a way that they form a hierarchy. Each element in the hierarchy is supposed to be independent, and a relative ratio scale of measurement is derived from pairwise comparisons of the elements in a level of the hierarchy with respect to an element of the preceding level. However, in many cases, there is interdependence among criteria and alternatives. The ANP can be used as an effective tool in those cases where the interactions among the elements of a system form a network structure [32]. The process of ANP comprises four major steps [31, 33, 34].

Step 1 (model construction and problem structuring). The problem should be stated clearly and decomposed into a rational system like a network. The structure can be obtained by the opinion of decision makers through brainstorming or other appropriate methods.

Step 2 (pairwise comparison matrices and priority vectors). In ANP, like AHP, decision elements at each component are compared pairwise with respect to their importance towards their control criterion, and the components themselves are also compared pairwise with respect to their contribution to the goal. Decision makers are asked to respond to a series of pairwise comparisons where two elements or two components at a time will be compared in terms of how they contribute to their particular upper level criterion. In addition, if there are interdependencies among elements of a component, pairwise comparisons also needed to be created, and an eigenvector can be obtained for each element to show the influence of other elements on it. The relative importance values are determined on a scale of 1-9 (see Table 11), where a score of 1 represents equal importance between the two elements and a score of 9 indicates the extreme importance of one element (row component in the matrix) compared to the other one (column component in the matrix).

A reciprocal value is assigned to the inverse comparison; that is, $a_{i j}=1 / a_{j i}$, where $a_{i j}\left(a_{j i}\right)$ denotes the importance of the $i$ th ( $j$ th) element compared to the $j$ th ( $i$ th) element. Like AHP, pairwise comparison in ANP is made in the framework of a matrix, and a local priority vector can be derived as an estimate of the relative importance associated with the elements (or components) being compared by solving the following formula:

$$
A w=\lambda_{\max } \cdot w,
$$

where $A$ is the matrix of pairwise comparison, $w$ is the eigenvector, and $\lambda_{\max }$ is the largest eigenvalue of $A$. Saaty (1980) [35] proposes several algorithms for approximating $w$. The following three-step procedure is used to synthesize priorities [31, 33-36]. 
(1) Sum the values in each column of the pairwise comparison matrix.

(2) Divide each element in a column by the sum of its respective column. The resultant matrix is referred to as the normalized pairwise comparison matrix.

(3) Sum the elements in each row of the normalized pairwise comparison matrix and divide the sum by the $n$ elements in the row. These final numbers provide an estimate of the relative priorities for the elements being compared with respect to its upper level criterion. Priority vectors must be derived for all comparison matrices.

Step 3 (supermatrix formation). The supermatrix concept is similar to the Markov chain process [34, 37]. To obtain global priorities in a system with interdependent influences, the local priority vectors are entered in the appropriate columns of a matrix, known as a supermatrix. As a result, a supermatrix is actually a partitioned matrix, where each matrix segment represents a relationship between two nodes (components or clusters) in a system $[33,34,38]$. Let the components of a decision system be $C_{k}, k=1,2, \ldots, n$, which has $m_{k}$ elements denoted as $e_{k 1}, e_{k 2}, \ldots, e_{k m k}$. The local priority vectors obtained in Step 2 are grouped and located in appropriate positions in a supermatrix based on the flow of influence from a component to another component or from a component to itself as in the loop $A$ standard form of a supermatrix as follows $[34,37]$ :

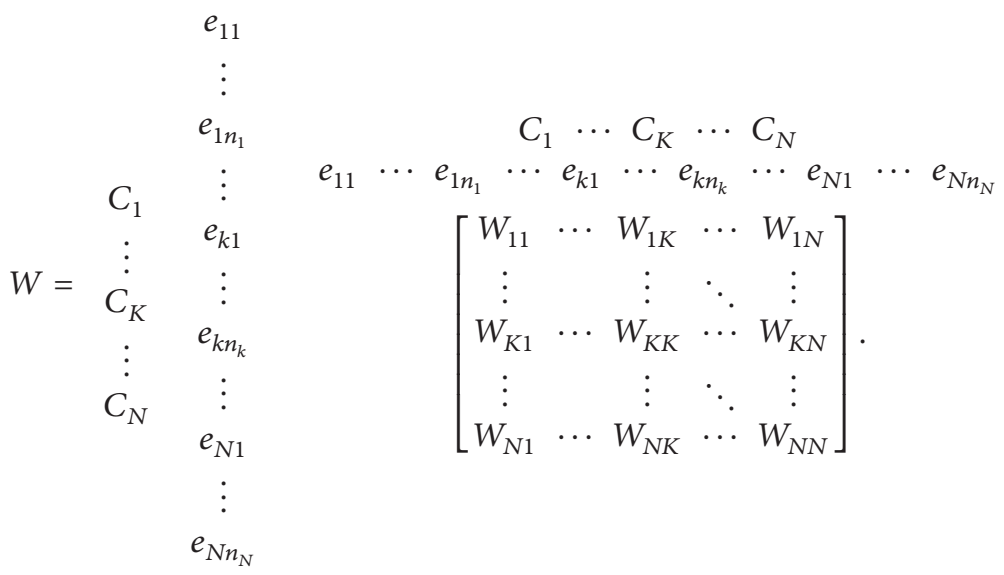

As an example, consider the supermatrix representation of a hierarchy with three levels $[34,37]$ :

$$
\mathbf{W}_{h}=\left[\begin{array}{ccc}
I & 0 & 0 \\
w_{21} & 0 & 0 \\
0 & \mathbf{W}_{32} & I
\end{array}\right],
$$

where $w_{21}$ is a vector that represents the impact of the goal on the criteria, $\mathbf{W}_{32}$ is a matrix that represents the impact of criteria on each of the alternatives, and $I$ is the identity matrix, and entries of zeros corresponding to those elements that have no influence.

For the above example, if the criteria are interrelated among themselves, a network replaces the hierarchy as shown in Figure $5[31,33]$. The $(2,2)$ entry of $\mathbf{W}_{n}$ given by $\mathbf{W}_{22}$ would indicate the interdependency, and the supermatrix would be $[34,37]$

$$
\mathbf{W}_{n}=\left[\begin{array}{ccc}
I & 0 & 0 \\
w_{21} & \mathbf{W}_{22} & 0 \\
0 & \mathbf{W}_{32} & I
\end{array}\right] .
$$

Note that a matrix can replace any zero in the supermatrix if there is an interrelationship of the elements in a component or between two components. Since there usually is interdependence among clusters in a network, the columns of a supermatrix usually sum to more than one. The supermatrix must be transformed first to make it stochastic; that is, each column of the matrix sums to unity. A recommended approach by Saaty (1996) [37] is to determine the relative importance of the clusters in the supermatrix with the column cluster (block) as the controlling component $[34,38]$. That is, the row components with nonzero entries for their blocks in that column block are compared according to their impact on the component of that column block [34, 37]. With pairwise comparison matrix of the row components with respect to the column component, an eigenvector can be obtained. This process gives rise to an eigenvector for each column block. For each column block, the first entry of the respective eigenvector is multiplied by all the elements in the first block of that column, the second by all the elements in the second block of that column, and so on. In this way, the block in each column of the supermatrix is weighted, and the result is known as the weighted supermatrix, which is stochastic [34].

Raising a matrix to powers gives the long-term relative influences of the elements on each other. To achieve a convergence on the importance of weights, the weighted 


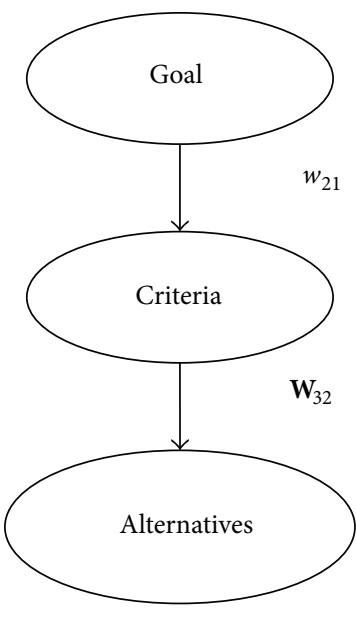

(a)

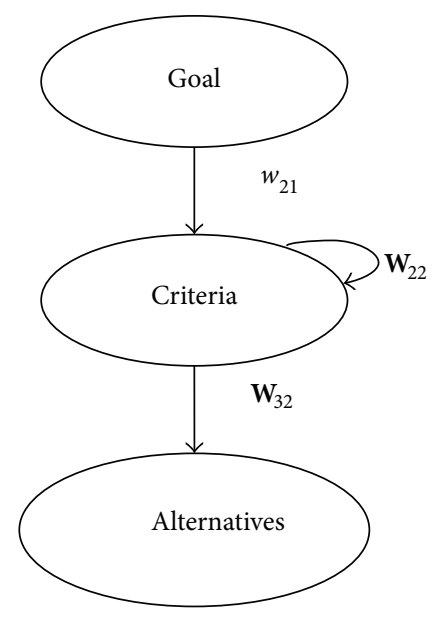

(b)
FIgURE 5: Hierarchy and network: (a) a hierarchy; (b) a network.

supermatrix is raised to the power of $2 k+1$, where $k$ is an arbitrarily large number, and this new matrix is called the limit supermatrix $[34,37]$. The limit supermatrix has the same form as the weighted supermatrix, but all the columns of the limit supermatrix are the same. By normalizing each block of this supermatrix, the final priorities of all the elements in the matrix can be obtained [34].

Step 4 (selection of the best alternatives). If the supermatrix formed in Step 3 covers the whole network, the priority weights of alternatives can be found in the column of alternatives in the normalized supermatrix. On the other hand, if a supermatrix only comprises components that are interrelated, additional calculation must be made to obtain the overall priorities of the alternatives. The alternative with the largest overall priority should be the one selected [34].

As mentioned before, ANP is a generalization of the AHP [33] and based on reasoning, knowledge, and experience of the experts in the field. ANP can act as a valuable aid for decision making involving both tangible and intangible attributes that are associated with the model under study. ANP relies on the process of eliciting managerial inputs, thus allowing for a structured communication among decision makers. Thus, it can act as a qualitative tool for strategic decision-making problems [34].

\section{Case Study}

In this section, selection of the best e-purse smart card technology is presented for the case of a company. Firstly, e-purse application is explained and then FAHP and ANP methods are applied to an e-purse smart card technology selection problem, respectively. Then, the results of FAHP and ANP methods are compared with each other. The case study is about the project of the e-purse application that is developed by Company $O$. The proposed model includes various usage fields about e-purse smart card: personalization of smart card and payment with smart card. Using e-purse smart card eliminates cash interchange and provides that process is made on smaller time and is enrolled, stock is controlled at workplace, and productivity is increased. In addition to interchange in company, this card also can be used as an identity card and entrance card. For the integration of this feature, cards must be personalized. Because of all this ease of use, all processes are made with only one smart card instead of using different smart card for each process. Finally, various characteristics that are necessary for a company are collected in a smart card. The software of these cards is programmed by Company O. Card technologies that provide required characteristics for programming are obtained from card companies. There are three alternatives; $\mathrm{AC}, \mathrm{TU}$, and $\mathrm{OB}$ card. These cards are compared according to some criteria and the best alternative has been selected. MCDM have not been used in the case company before; therefore, the selections have been made heuristics.

5.1. Determining the e-Purse Smart Card Technology Selection Criteria. In this study, the selection criteria were identified by decision makers. Thus, an interview was conducted with three decision makers who are chosen from different areas such as developers, system analysts, and academicians. Twelve subcriteria were determined to select the most convenient e-purse card technology alternative under the four main criteria. Also, three potential card technologies were considered for the selection. A detailed questionnaire related with criteria and alternatives was prepared for the selection process. During the identification of main and subcriteria, the opinions of experts from Company $\mathrm{O}$ were also taken into account.

For the three alternative card technologies, criteria are software technology and software performance, flexibility, cost, and service level. The definitions and subcriteria of the main criteria are summarized below, and also Table 1 shows the criteria and subcriteria.

Software Technology and Software Performance (S). It is the most important criterion during the selection of smart card for programming of e-purse card systems. It must be appropriate for software security and reliability. Performance and the quick response to software command are other subcriteria of the software technology and software performance. "Software development and easiness of software usage" (SDU), "speed of software working" (SS), "software security and software credibility" (SSC), and "technical sufficiency" (TS) are subcriteria of this criterion.

Flexibility $(F)$. Flexibility of smart card companies can be defined as compatible to response customer's request. This criterion contains ability to supply all products that customer has requested and their urgent product demand. "Easily supplying of card demands" (ESD), "supplying of urgent card demands" (SUD), and "supplying of different sector demands" (SSD) are subcriteria of this criterion.

Cost $(C)$. Software companies engaged with smart card technology want to supply material with minimum price to 
TABLE 1: Criteria and subcriteria for e-purse smart card technology selection.

\begin{tabular}{|c|c|}
\hline Criteria & Subcriteria \\
\hline \multirow{4}{*}{$\begin{array}{l}\text { Software } \\
\text { technology } \\
\text { and software } \\
\text { performance } \\
\text { (S) }\end{array}$} & $\begin{array}{l}\text { SDU: software development and easiness of } \\
\text { software usage }\end{array}$ \\
\hline & SS: speed of software working \\
\hline & SSC: software security and software credibility \\
\hline & TS: technical sufficiency \\
\hline \multirow{3}{*}{ Flexibility (F) } & ESD: easily supplying of card demands \\
\hline & SUD: supplying of urgent card demands \\
\hline & SSD: supplying of different sector demands \\
\hline \multirow[t]{2}{*}{ Cost (C) } & $\begin{array}{l}\text { AB: appropriate bidding according to other card } \\
\text { firms }\end{array}$ \\
\hline & $\begin{array}{l}\text { PR: price reduction in comparison with other } \\
\text { card firms according to cards quantity }\end{array}$ \\
\hline \multirow{3}{*}{$\begin{array}{l}\text { Service level } \\
\text { (SL) }\end{array}$} & SV: velocity of technical support after sale \\
\hline & $\begin{array}{l}\text { SDS: sufficiency of technical support department } \\
\text { after sale }\end{array}$ \\
\hline & OH: online technical help after sale \\
\hline
\end{tabular}

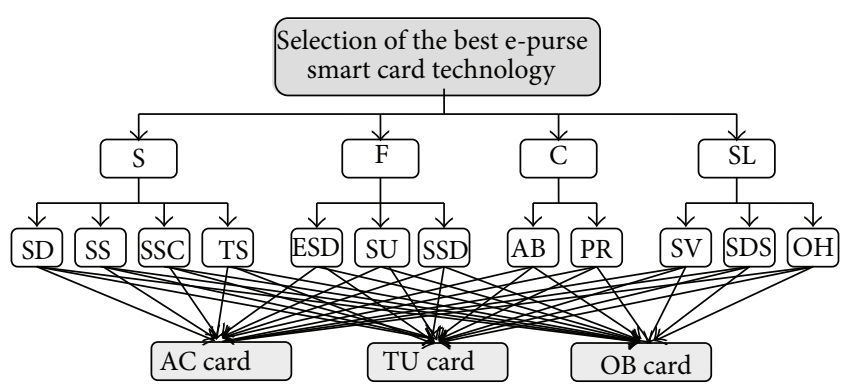

FIGURE 6: The hierarchy for selection of e-purse card technology problem.

raise profitability like all production companies. Provider's more appropriate price than the other providers and higher discount on the material according to the amount of purchased materials are subcriteria of cost. "Appropriate bidding according to other card firms" (AB) and "price reduction in comparison with other card firms according to cards quantity" (PR) are subcriteria of this criterion.

Service Level (SL). Qualified service of provider is an important factor and it is also significant for provider to be considered as high performance company by the customers. "Velocity of technical support after sale" (SV), "sufficiency of technical support department after sale" (SDS), and "online technical help after sale" $(\mathrm{OH})$ are subcriteria of this criterion.

According to explanations of the aforementioned main and subcriteria, a hierarchical structure for selection of e-purse card technology is shown in Figure 6.

5.2. Questionnaire. The three of decision makers are asked to make pairwise comparisons for main and subcriteria mentioned in Section 5.1. A questionnaire is provided to get the evaluations. The decision makers' linguistic preferences
TABLE 2: Triangular fuzzy number of linguistic terms.

\begin{tabular}{lc}
\hline Linguistic terms & Triangular fuzzy numbers \\
\hline Absolutely strong & $(7 / 2,4,9 / 2)$ \\
Very strong & $(5 / 2,3,7 / 2)$ \\
Fairly strong & $(3 / 2,2,5 / 2)$ \\
Weak & $(2 / 3,1,3 / 2)$ \\
Equal & $(1,1,1)$ \\
Weak & $(2 / 3,1,3 / 2)$ \\
Fairly strong & $(3 / 2,2,5 / 2)$ \\
Very strong & $(5 / 2,3,7 / 2)$ \\
Absolutely strong & $(7 / 2,4,9 / 2)$ \\
\hline
\end{tabular}

are converted into triangular fuzzy numbers by using Table 2 [39]. Following questions are given as a sample of questions from the questionnaire for the pairwise comparison matrices.

In the questionnaries, a check mark on the right side of the preference "equal" means that the criterion on the right side of the preference "equal" is more important than the one matching on the left side as it is specified by the check mark. A check mark on the left side of the preference "equal" means that the criterion on the left side of the preference "equal" is more important than the one matching on the right side as it is specified by the check mark [18]. A sample of the questionnaire forms used for comparisons of main and subcriteria is given in Table 3 .

With respect to the overall goal "selection of the best e-purse smart card technology," consider the following.

Question 1. How important is software technology and software performance $(\mathrm{S})$ when it is compared with flexibility $(\mathrm{F})$ ?

Question 2. How important is software technology and software performance $(\mathrm{S})$ when it is compared with cost $(\mathrm{C})$ ?

Question 3. How important is software technology and software performance (S) when it is compared with service level $(\mathrm{SL})$ ?

Question 4. How important is flexibility (F) when it is compared with cost $(\mathrm{C})$ ?

Question 5. How important is flexibility (F) when it is compared with service level (SL)?

Question 6. How important is cost (C) when it is compared with service level (SL)?

Other matrices are done with same method.

5.3. Numerical Applications of the Methods. In this section, the best e-purse card technology that will be used in Company O is selected with FAHP and ANP methods, respectively. A questionnaire is made in the company to establish importance weights (fuzzy preference numbers) that are necessary for selection of best card technology. The questionnaires facilitate the answering of pairwise comparison questions. 
TABLE 3: A sample from the questionnaire.

Selection of the best e-purse smart card technology

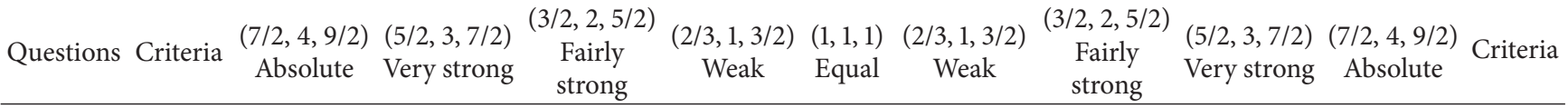

\begin{tabular}{lllllll}
\hline Q1 & $S$ & $X$ & $X X$ & F
\end{tabular}

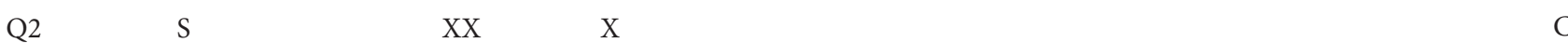

Q3 S $\quad$ X $\quad$ XX

Q4 F $\quad$ XXX

Q5 $\quad$ F $\quad$ XXX

Q6 C

TABLE 4: Evaluation results of the criteria with respect to the goal.

\begin{tabular}{lccrr}
\hline Main criteria & S & F & C & SL \\
\hline S & $(1.000,1.000,1.000)$ & $(1.500,2.289,2.797)$ & $(2.109,2.621,3.130)$ & $(1.778,2.289,2.797)$ \\
F & $(0.358,0.437,0.562)$ & $(1.000,1.000,1.000)$ & $(1.500,2.000,2.500)$ & $(0.400,0.500,0.667)$ \\
C & $(0.319,0.382,0.474)$ & $(0.400,0.500,0.667)$ & $(1.000,1.000,1.000)$ & $(0.400,0.500,0.667)$ \\
SL & $(0.358,0.437,0.562)$ & $(1.500,2.000,2.500)$ & $(1.500,2.000,2.500)$ & $(1.000,1.000,1.000)$ \\
\hline
\end{tabular}

5.3.1. Applying FAHP to e-Purse Smart Card Technology Selection Problem. Firstly, FAHP method is used for best e-purse card technology selection. In this method, the factors' fuzzy weights are calculated according to each other for selection of $\mathrm{AC}, \mathrm{TU}$, and $\mathrm{OB}$ card technologies. For this, criteria and subcriteria are listed for selecting card technologies. For determining the relative importance between main and subcriteria, three decision makers were asked to respond for pairwise comparisons. According to result of questionnaire, geometric mean is used to set pairwise comparisons.

Geometric means are obtained as follows. An example calculation is given.

The importance of "software technology and software performance (S)" is $(3 / 2,2,5 / 2),(3 / 2,2,5 / 2)$, and $(5 / 2,3,7 / 2)$ when it is compared with "flexibility $(\mathrm{F})$." Consider

$$
\begin{aligned}
& \left(\sqrt[3]{\left(\frac{3}{2} \times \frac{3}{2} \times \frac{5}{2}\right)}, \sqrt[3]{(2 \times 2 \times 3)}, \sqrt[3]{\left(\frac{5}{2} \times \frac{5}{2} \times \frac{7}{2}\right)}\right) \\
& =(1.500,2.289,2.797)
\end{aligned}
$$

The evaluation results are given in Table 4.

Fuzzy synthetic extent values are calculated by using evaluation results. Firstly, the values of fuzzy synthetic extents with respect to the main criteria are calculated. Calculation of $S_{1}$ is given as an example. The obtained values are shown in Table 5. Similar calculations are done for the other matrices. Table 5 depicts the results of the calculations. Consider

$$
\begin{gathered}
(1,1,1) \oplus(1.500,2.289,2.797) \oplus(2.109,2.621,3.130) \\
\oplus(1.778,2.289,2.797)=(6.387,8.199,9.724) .
\end{gathered}
$$

$$
\begin{aligned}
& ((1,1,1) \oplus(1.500,2.289,2.797) \oplus(2.109,2.621,3.130) \\
& \oplus(1.778,2.289,2.797)) \\
& +((0.358,0.437,0.562) \oplus(1,1,1) \oplus(1.500,2.000,2.500) \\
& +((0.319,0.382,0.474) \oplus(0.400,0.500,0.667) \\
& +((0.358,0.437,0.562) \oplus(1.500,2.000,2.500) \\
& \quad \oplus(1.500,2.000,2.500) \oplus(1,1,1)) \\
& =(16.122,19.960,23.823) \\
& S_{1}=(6.387,8.199,9.724) \otimes(16.122,19.960,23.823)^{-1} \\
& S_{1}=\left(\frac{6.387}{23.823}, \frac{8.199}{19.960}, \frac{9.724}{16.122}\right) \\
& S_{1}=(0.268,0.410,0.603)
\end{aligned}
$$

Importance weights of criteria are calculated by using fuzzy synthetic values. Then, probability of preference of one to the other is calculated. After this calculation, the weight vectors are calculated by using the results of probability of preference. The normalized weight vectors are values that are used for selection of e-purse smart card technologies. Tables $6,7,8$, and 9 are obtained as the priority weights of the alternatives according to each subcriterion. And the 
TABLE 5: Fuzzy synthetic extent values.

\begin{tabular}{lcccc}
\hline & $S_{1}$ & $S_{2}$ & $S_{3}$ & $S_{4}$ \\
\hline (1) Matrix & $(0.268,0.410,0.603)$ & $(0.137,0.197,0.293)$ & $(0.089,0.119,0.174)$ & $(0.183,0.272,0.407)$ \\
(2) Matrix & $(0.142,0.228,0.344)$ & $(0.094,0.142,0.232)$ & $(0.237,0.371,0.579)$ & $(0.159,0.258,0.426)$ \\
(3) Matrix & $(0.224,0.360,0.602)$ & $(0.206,0.331,0.563)$ & $(0.197,0.309,0.429)$ \\
(4) Matrix & $(0.430,0.613,0.859)$ & $(0.296,0.387,0.518)$ & \\
(5) Matrix & $(0.198,0.310,0.488)$ & $(0.255,0.413,0.652)$ & $(0.264,0.278,0.439)$ \\
(6) Matrix & $(0.396,0.545,0.742)$ & $(0.125,0.158,0.209)$ & $(0.212,0.297,0.413)$ \\
(7) Matrix & $(0.362,0.515,0.721)$ & $(0.131,0.167,0.223)$ & $(0.225,0.318,0.450)$ \\
(8) Matrix & $(0.395,0.545,0.826)$ & $(0.128,0.163,0.244)$ & $(0.135,0.292,0.449)$ \\
(9) Matrix & $(0.207,0.507,0.901)$ & $(0.128,0.164,0.279)$ & $(0.227,0.328,0.601)$ \\
(10) Matrix & $(0.344,0.519,0.751)$ & $(0.164,0.243,0.376)$ & $(0.161,0.238,0.365)$ \\
(11) Matrix & $(0.323,0.492,0.721)$ & $(0.189,0.279,0.421)$ & $(0.160,0.229,0.347)$ \\
(12) Matrix & $(0.359,0.513,0.718)$ & $(0.220,0.312,0.439)$ & $(0.136,0.176,0.242)$ \\
(13) Matrix & $(0.141,0.151,0.197)$ & $(0.501,0.575,0.764)$ & $(0.233,0.274,0.372)$ \\
(14) Matrix & $(0.130,0.171,0.247)$ & $(0.415,0.569,0.775)$ & $(0.180,0.261,0.369)$ \\
(15) Matrix & $(0.430,0.575,0.764)$ & $(0.200,0.274,0.372)$ & $(0.121,0.151,0.197)$ \\
(16) Matrix & $(0.368,0.545,0.766)$ & $(0.222,0.300,0.423)$ & $(0.123,0.155,0.215)$ \\
(17) Matrix & $(0.413,0.545,0.753)$ & $(0.206,0.293,0.392)$ & $(0.123,0.162,0.203)$ \\
\hline
\end{tabular}

TABLE 6: Summary combination of priority weights: subcriteria of software technology and software performance.

\begin{tabular}{lllcccr}
\hline Subcriteria & & SDU & SS & SSC & TS & \\
\hline Priority weights & & 0.199 & 0.000 & 0.493 & 0.308 & Alternative priority weight \\
\hline \multirow{3}{*}{ Alternatives } & AC & 0.940 & 0.764 & 0.890 & 0.537 & $\mathbf{0 . 7 9 1}$ \\
& TU & 0.000 & 0.000 & 0.000 & 0.093 & $\mathbf{0 . 0 2 9}$ \\
\hline
\end{tabular}

TABLE 7: Summary combination of priority weights: subcriteria of flexibility.

\begin{tabular}{lllllr}
\hline Subcriteria & & ESD & SUD & SSD & \\
\hline Priority weights & & 0.368 & 0.338 & 0.294 & Alternative priority weight \\
\hline \multirow{3}{*}{ Alternatives } & AC & 0.852 & 0.714 & 0.778 & $\mathbf{0 . 7 8 4}$ \\
& TU & 0.089 & 0.089 & 0.222 & $\mathbf{0 . 1 7 4}$ \\
& OB & 0.059 & 0.060 & 0.000 & $\mathbf{0 . 0 4 2}$ \\
\hline
\end{tabular}

TABLE 8: Summary combination of priority weights: subcriteria of cost.

\begin{tabular}{lcccc}
\hline Subcriteria & & AB & PR & \\
\hline Priority weights & & 0.781 & 0.219 & Alternative priority weight \\
\hline \multirow{3}{*}{ Alternatives } & AC & 0.000 & 0.000 & $\mathbf{0 . 0 0 0}$ \\
& TU & 1.000 & 1.000 & $\mathbf{1 . 0 0 0}$ \\
& OB & 0.000 & 0.000 & $\mathbf{0 . 0 0 0}$ \\
\hline
\end{tabular}

TABLE 9: Summary combination of priority weights: subcriteria of service level.

\begin{tabular}{llcccc}
\hline Subcriteria & & SV & SDS & OH & \\
\hline Priority weights & & 0.359 & 0.518 & 0.123 & Alternative priority weight \\
\hline \multirow{3}{*}{ Alternatives } & AC & 0.500 & 0.845 & 1.000 & $\mathbf{0 . 7 4 0}$ \\
& TU & 0.500 & 0.155 & 0.000 & $\mathbf{0 . 2 6 0}$ \\
& OB & 0.000 & 0.000 & 0.000 & $\mathbf{0 . 0 0 0}$ \\
\hline
\end{tabular}


TABLE 10: Summary combination of priority weights: main criteria of the goal.

\begin{tabular}{llccccc}
\hline Main criteria & & S & F & C & SL & \\
\hline Priority weights & & 0.622 & 0.065 & 0.000 & 0.312 & Alternative priority weights \\
\hline \multirow{3}{*}{ Alternatives } & AC & 0.791 & 0.784 & 0.000 & 0.740 & $\mathbf{0 . 7 7 4}$ \\
& TU & 0.029 & 0.174 & 1.000 & 0.260 & $\mathbf{0 . 1 1 1}$ \\
& OB & 0.861 & 0.861 & 0.672 & 0.769 & $\mathbf{0 . 1 1 5}$ \\
\hline
\end{tabular}

obtained priority weights of criteria are presented in Table 10 . An example calculation is given.

$$
\begin{aligned}
& \text { Consider matrix } \\
& \left.\begin{array}{l}
V\left(S_{1}>S_{2}\right)=1.000 \\
V\left(S_{1}>S_{3}\right)=1.000 \\
V\left(S_{1}>S_{4}\right)=1.000
\end{array}\right\} V\left(S_{1}>S_{2}, S_{3}, S_{4}\right) \\
& =(1.000,1.000,1.000) \\
& \min (1.000,1.000,1.000)=1.000 \\
& \left.\begin{array}{l}
V\left(S_{2}>S_{1}\right)=0.105 \\
V\left(S_{2}>S_{3}\right)=1.000 \\
V\left(S_{2}>S_{4}\right)=0.595
\end{array}\right\} V\left(S_{2}>S_{1}, S_{3}, S_{4}\right) \\
& =(0.105,1.000,0.595) \\
& \min (0.105,1.000,0.595)=0.105 \\
& V\left(S_{3}>S_{1}\right)=0.000 \\
& \left.V\left(S_{3}>S_{2}\right)=0.323\right\} V\left(S_{3}>S_{1}, S_{2}, S_{4}\right) \\
& V\left(S_{3}>S_{4}\right)=0.000 \\
& =(0.000,0.323,0.000) \\
& \min (0.000,0.323,0.000)=0.000 \\
& V\left(S_{4}>S_{1}\right)=0.502 \\
& \left.V\left(S_{4}>S_{2}\right)=1.000\right\} V\left(S_{4}>S_{1}, S_{2}, S_{3}\right) \\
& V\left(S_{4}>S_{3}\right)=1.000 \\
& =(0.500,1.000,1.000) \\
& \min (0.502,1.000,1.000)=0.502 \\
& W^{\prime}=(1.000,0.105,0.000,0.502) .
\end{aligned}
$$

Via normalization, the normalized weight vector is

$$
W=(0.622,0.065,0.000,0.312) .
$$

Similar calculations are done for the other matrices.

According to the final score, as seen in Table 10, "AC card" technology is the most appropriated e-purse smart card technology because it has the highest value with the \%77.4 priority weight.

5.3.2. Applying ANP to e-Purse Smart Card Technology Selection Problem. In the previous section, the best e-purse smart
TABLE 11: Nine-point intensity of importance scale and its description.

\begin{tabular}{lc}
\hline Definition & Intensity of importance \\
\hline Equally important & 1 \\
Moderately more important & 3 \\
Strongly more important & 5 \\
Very strongly more important & 7 \\
Extremely more important & 9 \\
Intermediate values & $2,4,6,8$ \\
\hline
\end{tabular}

card technology has been selected by using fuzzy AHP. According to the result of FAHP, AC card technology which has the highest value with the $\% 77.4$ priority weight is the best e-purse smart card technology. In this section, the best e-purse smart card technology is selected by using ANP method.

Both FAHP and ANP methods used the same criteria. A questionnaire is made to establish pairwise comparisons that are necessary for selection of best card technology. Decision makers made individual evaluations using the nine-point scale provided in Table 11 [40]. According to the result of the questionnaire, relationship between criteria is decided and pairwise comparisons are constructed. Network structure of the model is shown in Figure 7.

After the pairwise comparisons are completed, supermatrices are computed.

(1) The unweighted supermatrix is created directly from all local priorities derived from pairwise comparisons among elements influencing each other (see Figure 8).

(2) The weighted supermatrix is calculated by multiplying the values of the unweighted supermatrix with their affiliated cluster weights (see Figure 9).

(3) Composition of a limiting supermatrix takes place, which is created by raising the weighted supermatrix to powers until it stabilizes (see Figure 10).

Stabilization is achieved when all the columns in the supermatrix corresponding to any node have the same values. All of these steps are performed in Super Decisions, which is a software package developed for ANP applications by Saaty. In Figure 11, the column of "Normals" shows the results. According to the results, "AC card" technology which has the highest value with the $\approx \% 0.66$ priority weight is the most preferred e-purse smart card technology. 


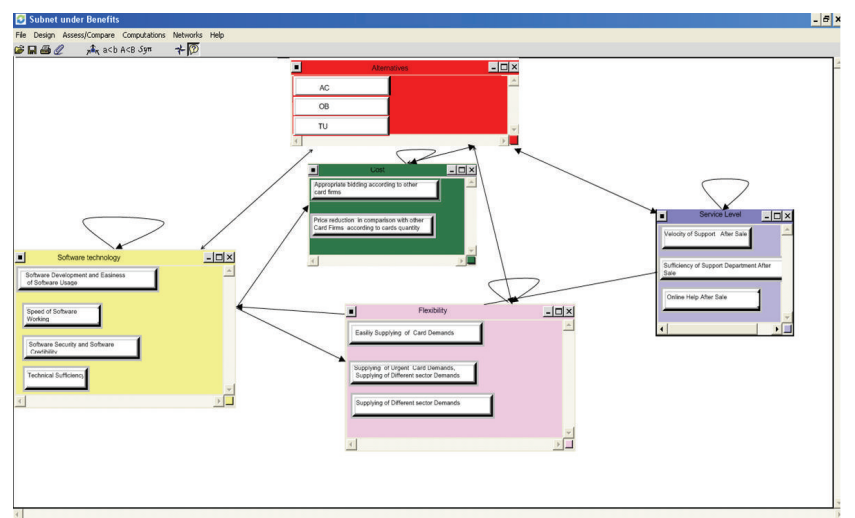

FIgURE 7: Network structure of the ANP e-purse smart card technology selection model.

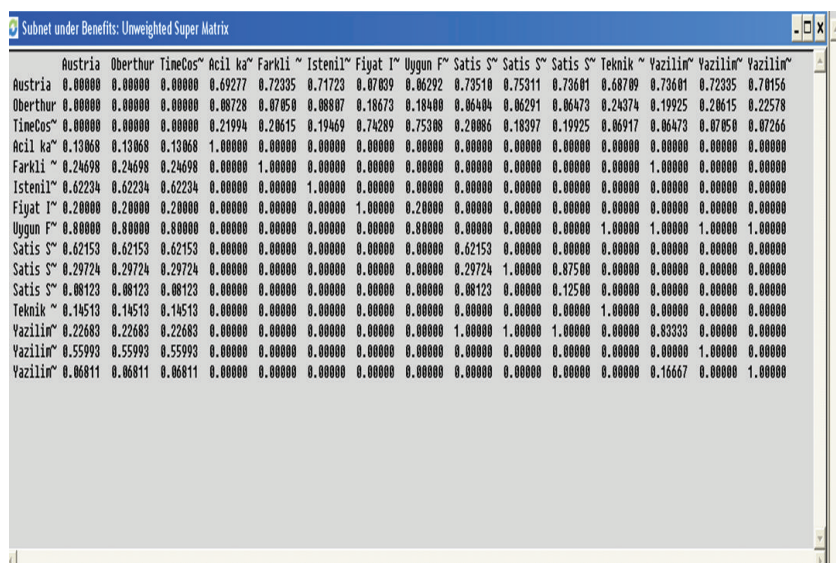

FIGURE 8: Unweighted super matrix.

5.4. Comparison of the Results. The comparison of the results provided from the FAHP and the ANP methods is illustrated in Figure 12. In FAHP method, as seen in Figure 12, "AC card" technology is ranked in the first place with the $\approx \% 77$ priority weight as the most appropriated e-purse smart card technology among other card technologies. Besides, "OB card" ( $\approx \% 12)$ and "TU card" ( $\approx \% 11)$ technologies with the values very close to each other come as second and third choice, respectively. Also, in ANP method, "AC card" technology is ranked in the first place with the $\approx \% 66$ priority weight among other card technologies. "OB card" ( $\approx \% 18)$ and "TU card" ( $\approx \% 17)$ technologies come as second and third choice, respectively.

When the results of FAHP and ANP methods are compared, it is seen that the most appropriated e-purse smart card technology is the same. "AC card" technology is the best technology according to both methods. But when the results are examined, it is seen that priority weights of the alternatives are not the same because of the relations between the criteria and the subcriteria in the methods. In the FAHP method, the relations between the criteria and the subcriteria are not considered but in the ANP method all of the external and internal dependences and also feedbacks are taken into consideration.

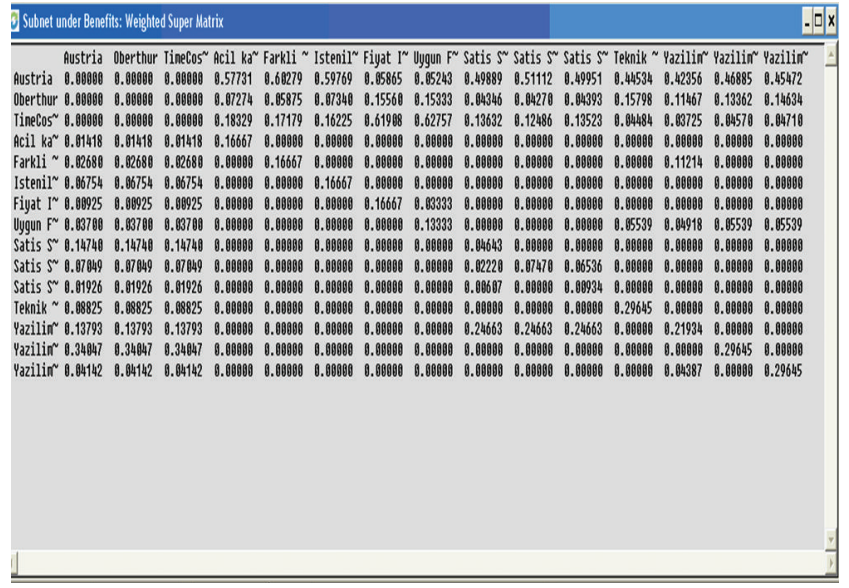

FIGURE 9: Weighted super matrix.

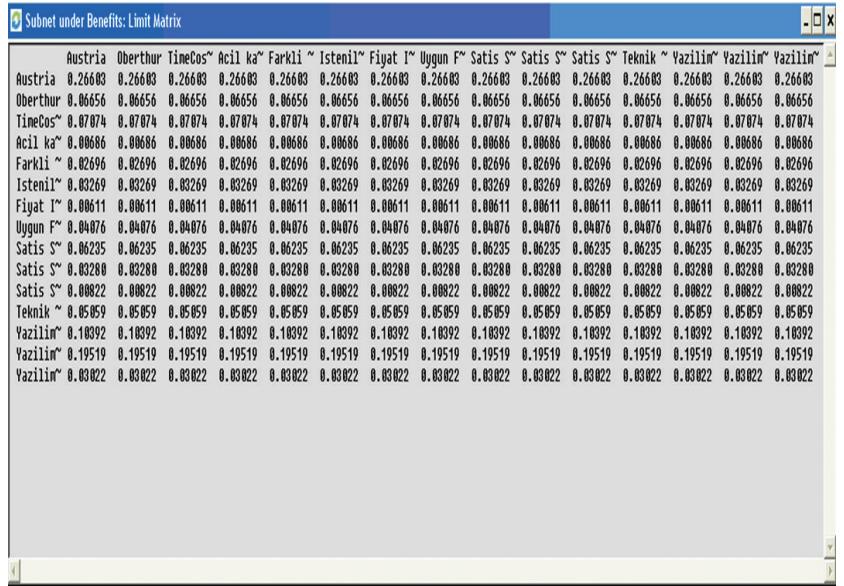

FIGURE 10: Limit matrix.

\section{Conclusion}

A field where decision making methods are applied is selection of card technologies. Usage of smart card technology increases with becoming widespread of the Internet. Selecting the best technology is decided as multiple dimension for software of smart card technologies that supplies customer demands.

The objective of this study is to identify important selection criteria to select the best e-purse smart card technology providing the most customer satisfaction. In the case study, at first, three decision makers are chosen from different areas such as developers, system analysts, and academicians. An interview is conducted with decision makers to identify the selection criteria and potential alternatives. Detailed questionnaires related with criteria and alternatives are prepared for determining the relative importance between main and subcriteria. Then, FAHP and ANP methods are applied to the e-purse smart card technology selection problem, respectively. Results of FAHP and ANP methods are compared with each other. According to the results of methods, it is seen that the best e-purse smart card technology is the same. "AC card" 


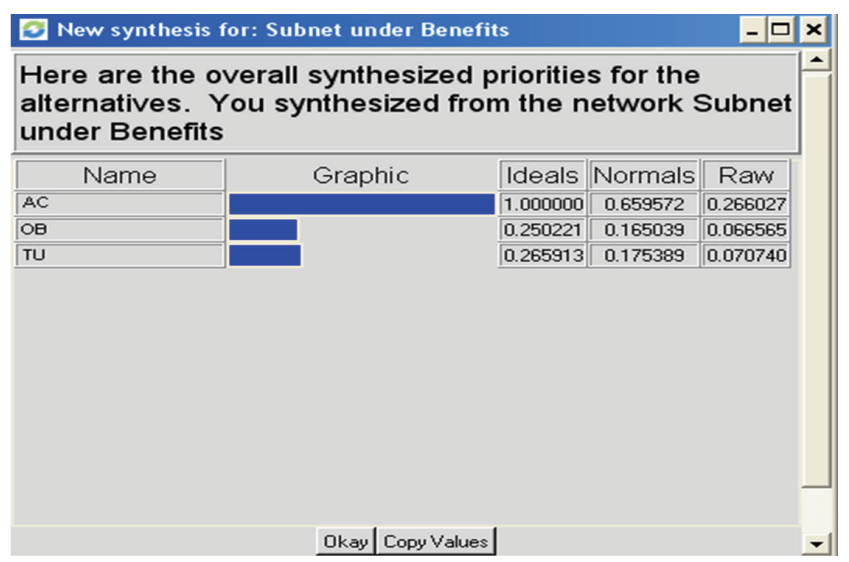

FIgURE 11: Priorities of the alternatives obtained by ANP method.

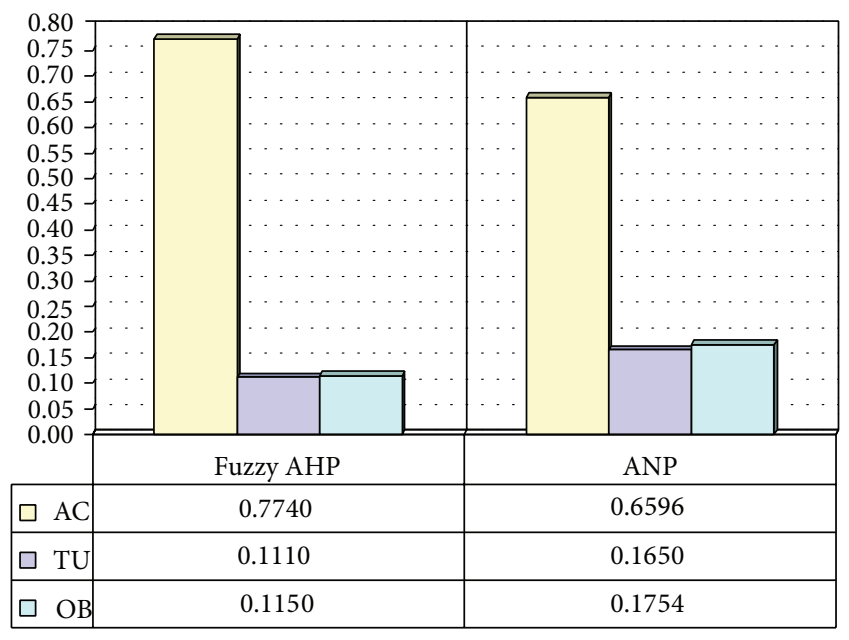

FIGURE 12: The results obtained from the FAHP and the ANP methods.

technology is the most appropriated card technology because it has the highest value than the others. But when the results are examined, it is also seen that there are some differences because of the relations between the criteria and subcriteria in the methods.

For further researches, these methods can be applied to other smart card application areas such as security, transportation, telecommunications, education, and healthcare. Besides, for selection of smart card type, smart card software, or payment systems these methods can be used.

For different smart card applications, the card properties which are not used in the comparison process of this study can be taken into consideration. And also the number of evaluation criteria and alternatives can be increased. Additionally, other multicriteria decision making methods such as TOPSIS and ELECTRE can be used to solve e-purse smart card technology selection problem. The obtained results of other methods can be compared with the results of this study.

\section{Conflict of Interests}

The authors declare that they have no conflict of interests regarding the publication of this paper.

\section{References}

[1] İ. Daşdemir and E. Güngör, "Çok boyutlu karar verme metotlar1 ve ormancilıkta uygulama alanları," ZKÜ Bartın Orman Fakültesi Dergisi, vol. 4, no. 4, pp. 1-16, 2005.

[2] J. Domingo-Ferrer, J. Posegga, F. Sebé, and V. Torra, "Advances in smart cards," Computer Networks, vol. 51, no. 9, pp. 22192222, 2007.

[3] W. Rankl and W. Effing, Smart Card Handbook, John Wiley \& Sons, Chichester, UK, 3rd edition, 2003.

[4] C. Liu, P. Yang, Y. Yeh, and B. Wang, "The impacts of smart cards on hospital information systems - an investigation of the first phase of the national health insurance smart card project in Taiwan," International Journal of Medical Informatics, vol. 75, no. 2, pp. 173-181, 2006.

[5] K. M. Shelfer and J. D. Procaccino, "Smart card evolution," Communications of the ACM, vol. 45, no. 7, pp. 83-88, 2002.

[6] Government Smart Card Handbook, U.S. General Services Administration, 2004, http://www.smartcardalliance.org/resources/pdf/smartcardhandbook.pdf.

[7] W. Rankl, Smart Card Applications, John Wiley \& Sons, Chichester, UK, 2007.

[8] Smart-Card Devices and Applications, 2001, http://www.netcaucus.org/books/egov2001/pdf/SmartCar.pdf.

[9] http://www.mmi.co.in/smartcards/AboutSmartCard.pdf.

[10] United States General Accounting Office, "Electronic Government: progress in promoting adoption of smart card technology," Tech. Rep. GAO-03-144, GAO, 2003.

[11] S. Rogerson, "Smart card technology," IMIS Journal, vol. 8, no. $1,1998$.

[12] C. H. M. Lee, Y. W. Cheng, and A. Depickeré, "Comparing smart card adoption in Singapore and Australian universities," International Journal of Human Computer Studies, vol. 58, no. 3, pp. 307-325, 2003.

[13] A.-C. Cheng, C.-H. Chen, and C.-Y. Chen, "A fuzzy multiple criteria comparison of technology forecasting methods for predicting the new materials development," Technological Forecasting and Social Change, vol. 75, no. 1, pp. 131-141, 2008.

[14] A. Azadeh and H. R. Izadbakhsh, "A multi-variate/multiattribute approach for plant layout design," International Journal of Industrial Engineering: Theory Applications and Practice, vol. 15, no. 2, pp. 143-154, 2008.

[15] Y.-M. Wang, Y. Luo, and Z. Hua, "On the extent analysis method for fuzzy AHP and its applications," European Journal of Operational Research, vol. 186, no. 2, pp. 735-747, 2008.

[16] G. N. Serbest and Ö. Vayvay, "Selection of the most suitable distribution channel using fuzzy analytic hierarchy process in Turkey," International Journal of Logistics Systems and Management, vol. 4, no. 5, pp. 487-505, 2008.

[17] O. Durán and J. Aguilo, "Computer-aided machine-tool selection based on a Fuzzy-AHP approach," Expert Systems with Applications, vol. 34, no. 3, pp. 1787-1794, 2008.

[18] C. Kahraman, U. Cebeci, and D. Ruan, "Multi-attribute comparison of catering service companies using fuzzy AHP: the case of Turkey," International Journal of Production Economics, vol. 87, no. 2, pp. 171-184, 2004.

[19] F. T. Bozbura, A. Beskese, and C. Kahraman, "Prioritization of human capital measurement indicators using fuzzy AHP," Expert Systems with Applications, vol. 32, no. 4, pp. 1100-1112, 2007. 
[20] P. J. M. van Laarhoven and W. Pedryca, "A fuzzy extension of Saaty's priority theory," Fuzzy Sets and Systems, vol. 11, pp. 229241, 1983.

[21] M. Dağdeviren and I. Yüksel, "Developing a fuzzy analytic hierarchy process (AHP) model for behavior-based safety management," Information Sciences, vol. 178, no. 6, pp. 17171733, 2008.

[22] J. J. Buckley, "Fuzzy hierarchical analysis," Fuzzy Sets and Systems, vol. 17, no. 1, pp. 233-247, 1985.

[23] W. Zhang, Q. Zhang, and H. Karimi, "Seeking the important nodes of complex networks in product R\&D team based on fuzzy AHP and TOPSIS," Mathematical Problems in Engineering, vol. 2013, Article ID 327592, 9 pages, 2013.

[24] W. Zhang and Q. Zhang, "Multi-stage evaluation and selection in the formation process of complex creative solution," Quality \& Quantity, 2013.

[25] D. Y. Chang, "Applications of the extent analysis method on fuzzy AHP," European Journal of Operational Research, vol. 95, no. 3, pp. 649-655, 1996.

[26] C. E. Bozdağ, C. Kahraman, and D. Ruan, "Fuzzy group decision making for selection among computer integrated manufacturing systems," Computers in Industry, vol. 51, no. 1, pp. 13-29, 2003.

[27] C. Kahraman, D. Ruan, and I. Doğan, "Fuzzy group decisionmaking for facility location selection," Information Sciences, vol. 157, no. 1-4, pp. 135-153, 2003.

[28] S. Önüt, T. Efendigil, and S. S. Kara, "A combined fuzzy MCDM approach for selecting shopping center site: an example from Istanbul, Turkey," Expert Systems with Applications, vol. 37, no. 3, pp. 1973-1980, 2010.

[29] S. Önüt, U. M. Tuzkaya, and N. Saadet, "Multiple criteria evaluation of current energy resources for Turkish manufacturing industry," Energy Conversion and Management, vol. 49, no. 6, pp. 1480-1492, 2008.

[30] T. L. Saaty and L. G. Vargas, Decision Making with the Analytic Network Process: Economic, Political, Social and Technological Applications with Benefits, Opportunities, Costs and Risks, Springer, Pittsburgh, Pa, USA, 2006.

[31] M. Dağdeviren and İ. Yüksel, "Personnel selection using analytic network process," İstanbul Ticaret Üniversitesi Fen Bilimleri Dergisi, vol. 6, pp. 99-118, 2007.

[32] E. E. Karsak, S. Sözer, and S. E. Alptekin, "Product planning in quality function deployment using a combined analytic network process and goal programming approach," Computers and Industrial Engineering, vol. 44, no. 1, pp. 171-190, 2002.

[33] S. H. Chung, A. H. I. Lee, and W. L. Pearn, "Analytic network process (ANP) approach for product mix planning in semiconductor fabricator," International Journal of Production Economics, vol. 96, no. 1, pp. 15-36, 2005.

[34] C. W. Chang, C. Wu, and H. C. Chen, "Analytic network process decision-making to assess slicing machine in terms of precision and control wafer quality," Robotics and Computer-Integrated Manufacturing, vol. 25, no. 3, pp. 641-650, 2009.

[35] T. L. Saaty, The Analytic Hierarchy Process, McGraw-Hill, New York, NY, USA, 1980.

[36] L. M. Meade and A. Presley, "R\&D project selection using the analytic network process," IEEE Transactions on Engineering Management, vol. 49, no. 1, pp. 59-66, 2002.

[37] T. L. Saaty, Decision Making with Dependence and Feedback: The Analytic Network Process, RWS Publications, Pittsburgh, Pa, USA, 1996.
[38] L. M. Meade and J. Sarkis, "Analyzing organizational project alternatives for agile manufacturing processes: an analytical network approach," International Journal of Production Research, vol. 37, no. 2, pp. 241-261, 1999.

[39] H. Başligil, "The fuzzy analytic hierarchy process for software selection problems," Journal of Engineering and Natural Sciences, vol. 3, pp. 24-33, 2005.

[40] M. Dağdeviren, S. Yavuz, and N. Kılınç, "Weapon selection using the AHP and TOPSIS methods under fuzzy environment," Expert Systems with Applications, vol. 36, no. 4, pp. 81438151, 2009. 


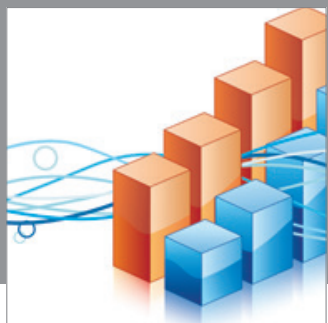

Advances in

Operations Research

mansans

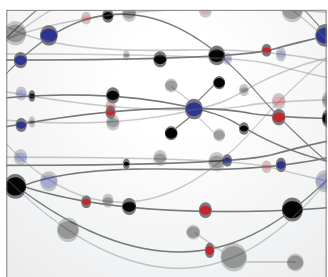

The Scientific World Journal
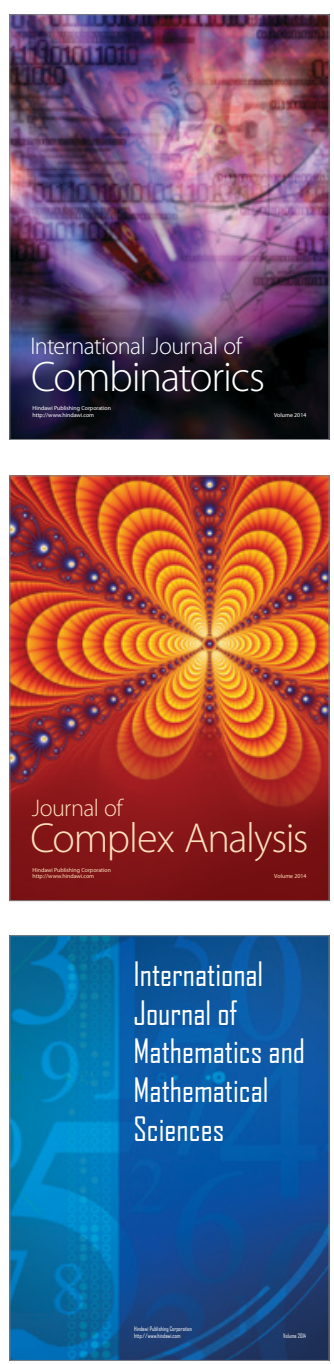
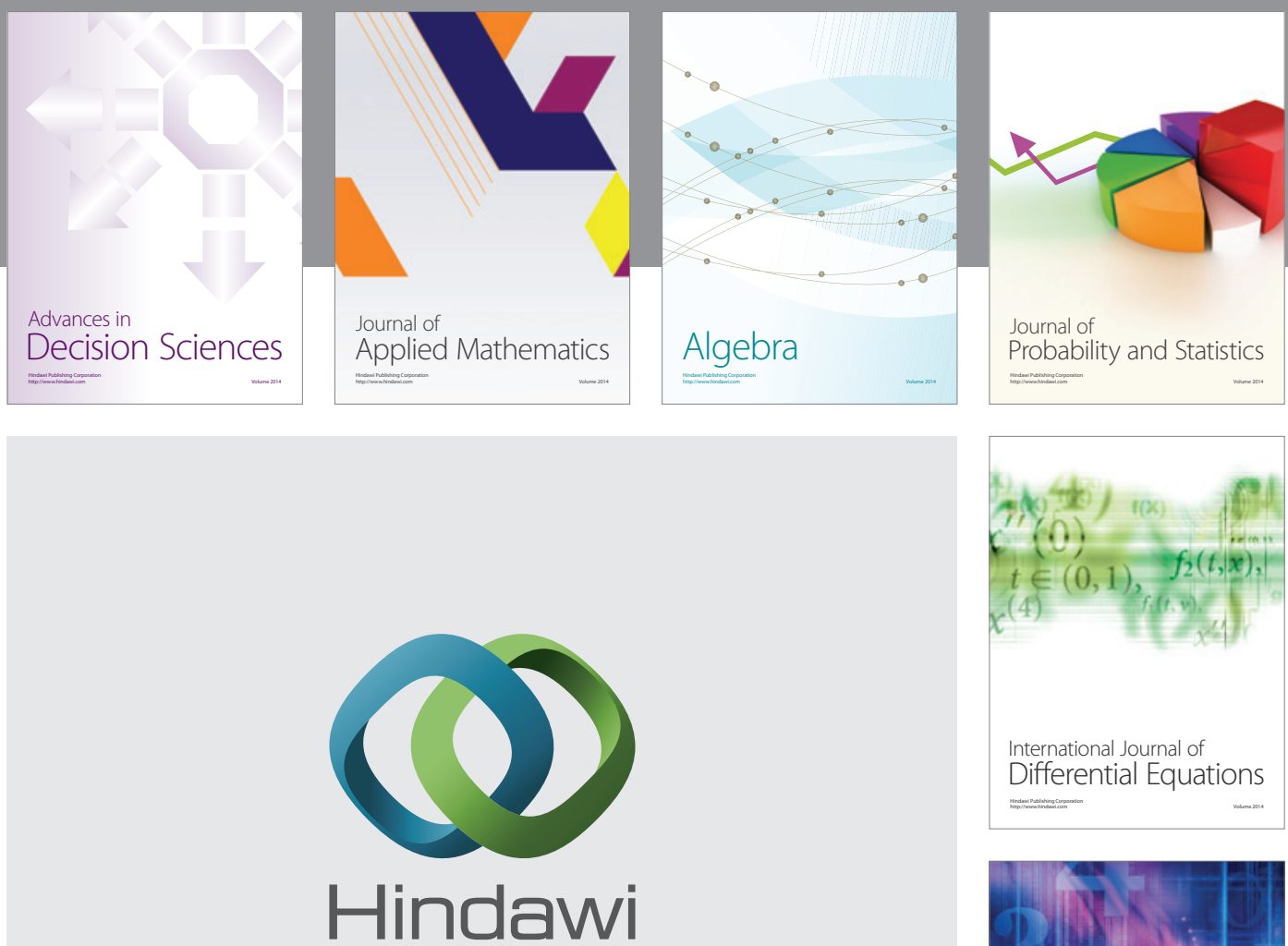

Submit your manuscripts at http://www.hindawi.com
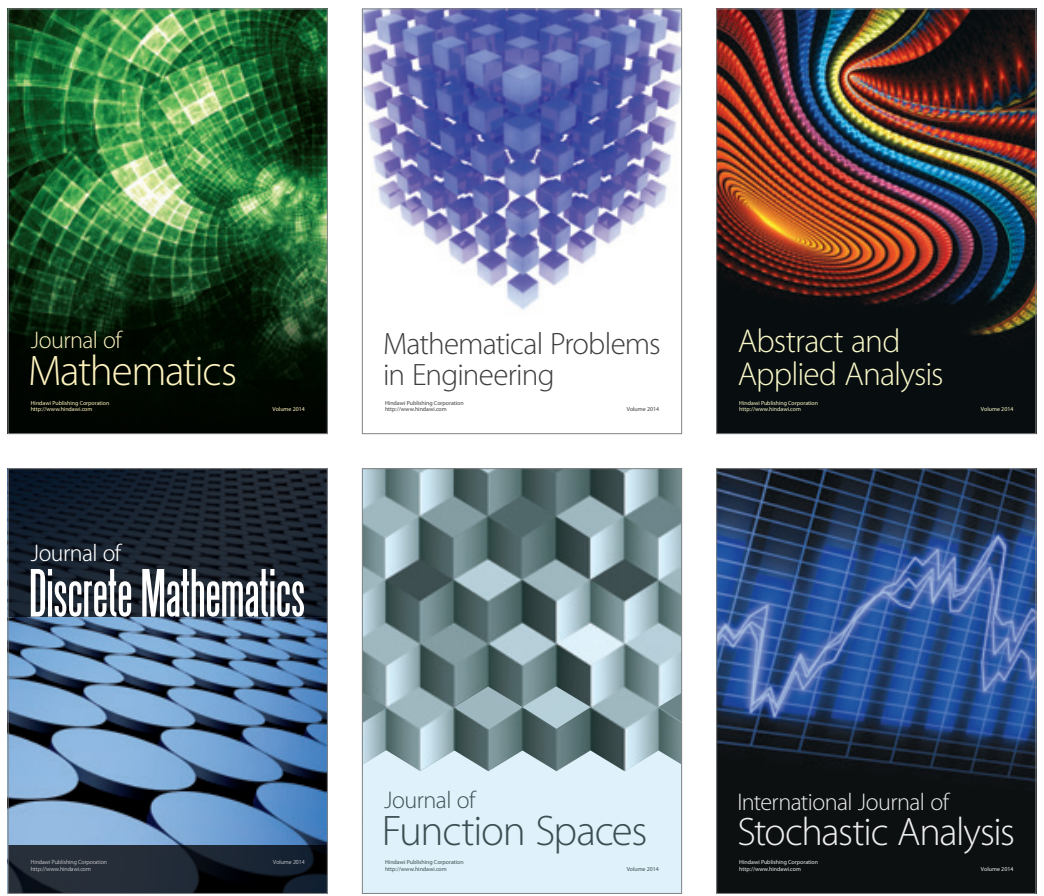

Journal of

Function Spaces

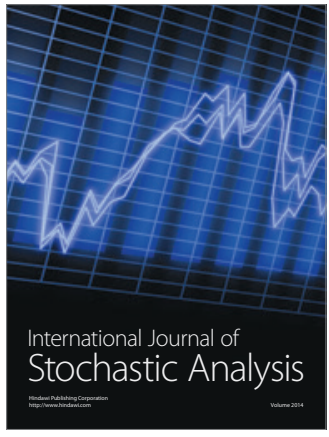

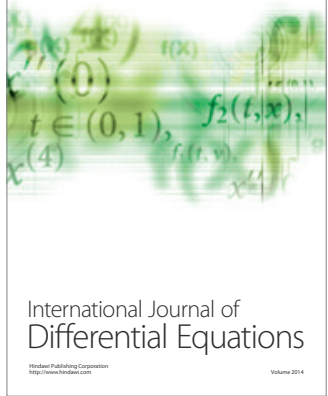
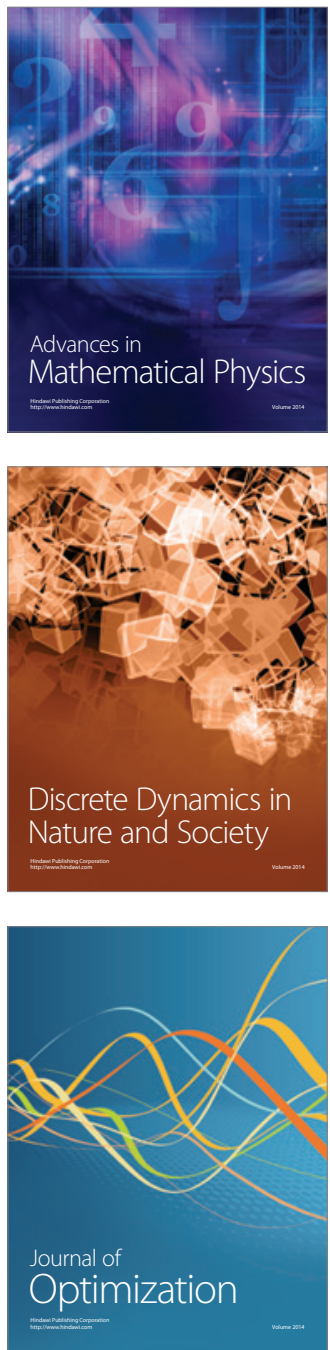